\title{
Rolling technique for treatment of left displacement of the large colon in horses: 11 cases (2004-2009)
}

\author{
[Técnica do rolamento para o tratamento de deslocamento à esquerda do cólon maior \\ em equinos: 11 casos (2004-2009)] \\ P.A. Canola ${ }^{1}$, J.C. Lacerda Neto ${ }^{2}$, J.C. Canola ${ }^{2}$ \\ ${ }^{1}$ Universidade Federal do Tocantins - EMVZ - Araguaína, TO \\ ${ }^{2}$ Universidade Estadual Paulista - FCAV - Jaboticabal, SP
}

\begin{abstract}
The left displacement of the large colon, a condition that commonly occurs in horses, has two clinical manifestations. Different treatments including medical treatment, rolling the horse under general anesthesia or surgical correction have been recommended. The diagnosis can often be made by rectal examination and confirmed by percutaneous ultrasonography. During the period between 2004 and 2009, 11 horses were treated for left displacement of the large colon by rolling the horses under general anesthesia, using a slightly different technique than the ones previously described. The clinical case selection was based on rectal palpation confirmed with ultrasonogram. Nine animals were successfully treated and two had to be submitted to surgery after three attempts of rolling. No short or long term complications were observed after the procedure. Only one animal had a recurrence of the clinical manifestation 10 months after the first treatment and was successfully rolled once again. Despite a bit different from the other rolling procedures, this also proved to be an effective procedure. Rolling a horse even when attempted more than once showed to be a safe procedure, however, we reinforce the need for special attention following the procedure in order to establish proper emergency procedures in case complications occur.
\end{abstract}

Keywords: rolling, ultrasonography, equine, colic, acute abdomen

\section{RESUMO}

Durante o período de 2004 a 2009, 11 animais foram tratados para o deslocamento à esquerda do cólon maior, por meio da técnica de rolamento sob anestesia geral, com uma técnica distinta das demais previamente descritas. A seleção dos casos foi baseada nos achados da palpação retal e confirmada ultrassonograficamente. Nove animais foram tratados com sucesso e dois foram submetidos ao tratamento cirúrgico após três tentativas de rolamento. Não foram observadas complicações decorrentes do procedimento a curto e a longo prazos. Somente um animal apresentou recidiva do quadro clínico 10 meses após o tratamento e foi novamente submetido ao rolamento. Apesar da diferença com relação às outras técnicas, esta também se mostrou eficaz. O rolamento, mesmo quando realizado mais de uma vez, mostrou ser um procedimento seguro, porém enfatiza-se a necessidade de cuidados especiais aos animais após a sua realização, pois medidas emergenciais podem ser necessárias caso complicações decorrentes desta técnica ocorram.

Palavras-chave: rolamento, ultrassonografia, equinos, cólica, abdômen agudo

\section{INTRODUCTION}

The large colon can become entrapped between the left kidney and spleen or between the spleen and left body wall. Both are referred to as left

Recebido em 11 de maio de 2011

Aceito em 9 de janeiro de 2013

E-mail: pacanola@yahoo.com.br dorsal displacement of the large colon (Santschi et al., 1993; Parks, 1996), a condition that commonly occurs in horses (Huskamp, 1987; Deen, 1990). It can result in either complete or incomplete displacement of substantial portions of the large colon over the nephrosplenic 
ligament, typically in a cranial to caudal direction (Huskamp and Kopf, 1980a; Huskamp and Kopf, 1980b). It is observed more frequently in middle-aged horses, geldings and large horses with an anatomically atypical nephrosplenic space (Huskamp and Kopf, 1980a; Huskamp, 1987; Burba and Moore, 1997).

The diagnosis of left dorsal displacement of the large colon can often be performed by rectal examination (Huskamp and Kopf, 1980a; Hardy, 2008) which reveals colon bands originating from the nephrosplenic space (Abutarbush and Naylor, 2005). The diagnosis can be confirmed by percutaneous ultrasonography of the upper portion of the left flank. The imaging of the dorsal aspect of the spleen, and often of the kidney, is obliterated by the displaced large colon (Santschi et al., 1993; Burba and Moore, 1997). The left kidney might be imaged in some horses presenting nephrosplenic entrapment if the colon caudal to the kidney contains ingesta and the entrapped colon is relatively free of gas (Santschi et al., 1993).

Differing treatment approaches for left dorsal displacement of the large colon have been recommended depending on the severity of the colic signs, and include medical treatment with intravenous administration of phenylephrine, rolling the horse under general anesthesia or surgical correction (Huskamp and Kopf, 1980a; Huskamp and Kopf, 1980b; Hardy, 2008). Surgical treatment is often used, but has potential problems including higher cost, longer convalescence period, and the requirement of specialized equipment or a hospital facility (Abutarbush and Naylor, 2005).

Boening and von Saldern (1985), and Kalsbeek (1985) were the first to separately describe a non-surgical method to correct nephrosplenic entrapment of the left colon by rolling the horse under general anesthesia. Bonfig and Huskamp (1986) presented a review of both techniques, including their own results on the non-surgical treatment, and Kalsbeek (1989) reported a simplified technique used in 26 horses.

Most recently the administration of phenylephrine diluted in saline for five minutes, followed by jogging the horse for 15 minutes has been advocated as the initial treatment in early referred cases with no distention (Hardy, 2008).
It appears to be the method with lowest cost, fewest complications and effort because general anesthesia is not required (Abutarbush and Naylor, 2005). In cases of gas distention, or if exercising the animal after phenylephrine administration does not solve the issue, rolling the patient under general anesthesia can be performed (Hardy, 2008).

Despite the fact that the rolling technique and its variations are long described in the equine practice, in our hospital the attempt of rolling a horse with left displacement of the large colon had never been performed until 2004. Preceding this period, all animals were treated surgically as stated by Markel et al. (1985), regardless of the degree of large colon displacement.

Considering the previous information, the results of a technique variation for non-surgical treatment of left displacement of the large colon by rolling the horses are shown here. Eleven animals were submitted to the procedure during the period from 2004 to 2009.

\section{MATERIALS AND METHODS}

During the period comprehended between 2004 and 2009, among the colic cases presented at the University's Veterinary Hospital, 11 horses; seven geldings, two stallions and two mares, were submitted to a non-surgical treatment for left displacement of the large colon. The decision to perform the procedure was based upon rectal palpation by the chief instructor of equine medicine. Seven animals presented a displaced colon located between the left body wall and the spleen. The other four presented a large colon completely entrapped into the nephrosplenic ligament. The average time set of clinical signs for abdominal discomfort previous to hospitalization was $16 \pm 15$ hours. Additionally, the most undesirable clinical presentation (large colon completely entrapped into the nephrosplenic ligament) was observed on the animals with longer time set of clinical signs.

Upon hospital arrival all animals presented mild to moderate recurrent signs of pain and were intubated for gastric emptying before rectal palpation. No considerable amount of reflux was observed in any of the animals. 
After clinical examination and peritoneal fluid gross analysis (aspect and color), rectal palpation was performed. The findings included bands originating from the nephrosplenic space running caudally and ventrally, with the pelvic flexure located above the nephrosplenic ligament in four animals. On the other seven, the findings also included colon bands running caudally and ventrally originating from between the body wall and an enlarged spleen.

Ventral and medial displacement and enlargement of the spleen could be felt in all animals. Not all nephrosplenic ligaments or left kidneys could be felt because of the body size of some of the animals. No special attention was given to how much colon was entrapped or presence of edema in the colonic wall. All colons presented mild distention due to gas caused be colonic partial stasis.

Diagnosis confirmation was made by percutaneous ultrasound examination following rectal palpation. After clipping the left paralumbar fossa, a $7.5 \mathrm{MHz}$ linear transducer (Scanner 200, Pie Medical Inc., Maastricht, Holland) was used to evaluate the abdominal cavity. The presence of left large colon displacement was confirmed ultrasonographically, on a transversal view. If the ultrasonographic appearance of the dorsal aspect of the spleen was obliterated and the kidney could not be visualized because of the colon gas echo, a diagnosis of nephrosplenic entrapment was confirmed, whereas if the entire image of the spleen was obscured by a gas echo, a displacement of the large colon was diagnosed. Percutaneous ultrasonography was performed on the left paralumbar fossa, bordered cranially by the $17^{\text {th }}$ rib space, dorsally by the ventral lumbar muscles and caudally by the cranial thigh musculature (Santschi et al., 1993).

All animals were positioned at the anesthesia induction/recovery room and submitted to general anesthesia as follows: Sedation with intravenous administration of xylazine (0.5mg.kg-1) (Rompum®, BAYER, São Paulo, Brazil). Guaifenesin (100mg. $\left.\mathrm{kg}^{-1}\right)$ diluted in $500 \mathrm{~mL}$ of $5 \%$ glucose solution (JP Pharmaceuticals, Ribeirão Preto, Brazil) with an additional $30 \mathrm{mg}$ of midazolam hydrochloride (Dormire®, CRISTÁLIA, São Paulo, Brazil) was administered intravenously 5 to 10 minutes following xylazine administration. The animals were than induced to general anesthesia with intravenous administration of $10 \%$ ketamine (1$2 \mathrm{mg} \cdot \mathrm{kg}^{-1}$ ) (Vetanarcol®, KONIG S.A, Buenos Aires, Argentina). After tracheal intubation and inhalant general anesthesia (Takaoka ${ }^{\circledR}$, São João Clímaco, Brazil) maintenance with halothane (Tanohalo®, CRISTÁLIA, São Paulo, Brazil) the animals were positioned in right lateral recumbence.

The hind limbs were than hoisted (Mod. BSTEW, Berg Steel, Araras, Brazil) until they were set at a $30^{\circ}$ to $40^{\circ}$ degree angle to the ground. The abdomen was then vigorously shaken for about one minute. Afterwards, the hind limbs were lowered to the ground and all members tied on together at the pastern region with a short rope. As follows, another rope (longer than the previous one) was firmly tied on the first one and passed under the animals' body.

First the tracheal tube was disconnected to the general anesthesia equipment and the rope was vigorously pulled by two or three persons so the animal could turn over its legs in a clockwise direction and stop at its initial recumbent position. Before recovery from general anesthesia, rectal palpation was performed with the animal still on right lateral recumbence. If necessary the procedure was repeated once or twice before the animal was allowed to recovery from anesthesia or sent to surgery. Rectal palpation was performed after each rolling attempt. Following recovery another ultrasound examination was performed to confirm the repositioning of the large colon.

\section{RESULTS}

Of all animals submitted to the procedure, nine $(81.8 \%)$ had a positive recovery in which seven were rolled only once and the other two three times before colon replacement could be diagnosed by rectal palpation and confirmed ultrasonographically. The animals that needed more attempts were the ones with an entrapped colon into the nephrosplenic ligament. The other seven successfully treated after one attempt were the ones presenting with just a displaced colon in between the left body wall and spleen.

All animals were closely observed until they were discharged from the hospital without 
presenting short term recurrence of the process or possible complications resulting from the procedure. Only one of them was presented to the hospital 10 months following treatment with recurrence of the clinical manifestation. The animal was again successfully rolled.

The rolling procedure used for correction of left displacement of the large colon removed the need for abdominal surgery in $81.8 \%$ of our treated animals. Only two cases had to be submitted to surgery afterwards to correct the displacement. In both animals three rolling attempts were made before they were sent to surgery. These animals were in the group presenting a displaced colon entrapped into the nephrosplenic ligament.

\section{DISCUSSION}

The clinical findings on the horses submitted to the procedure were similar to previous reports (Hackett, 1985; Huskamp, 1987; Kopf, 1987; Kalsbeek, 1989). Rectal manipulation during rolling the horse was not performed in any of the animals due to the risk of rectal tearing (Kalsbeek, 1989).

The non-surgical method used for correction of left displacement of the large colon removed the need for abdominal surgery in $81.8 \%$ of our treated animals, thereby saving a great deal of time and money as well as preventing post-operative complications such as recurrent colic episodes caused mostly by adhesions, wound infections, incision hernias and septic thrombophlebitis (Kalsbeek, 1989; Freeman et al., 2000; van den Boom and van der Velden, 2001; Abutarbush and Naylor, 2005; Mair and Smith, 2005; Mezerova and Zert, 2008).

Although slightly different than the previous rolling maneuvers described in literature, our rolling technique achieved the same preceding successful rates (Hackett, 1983; Kalsbeek, 1989; Deen, 1990; Hardy, 2008). It was more effective on the cases in which the left colon was slightly displaced in between the body wall and the spleen. Therefore, repositioning of the colon could have happened before the rolling procedure, following anesthesia induction or when the patients were hoisted and had their abdomen vigorously shaken. According to Boening and von Saldern (1985), in some cases nephrosplenic entrapment has been theorized to correct itself after anesthesia induction.

Considering that the rolling procedure worked better on the animals with the colon displaced in between the spleen and the body wall, these specific cases could probably have been solved solely with intravenous administration of phenylephrine diluted in saline, followed by exercising the animals (Abutarbush and Naylor, 2005; Hardy, 2008). However, no attempts of repositioning the large colon by splenic contraction followed by administration of phenylephrine diluted in saline were performed. There have been indications that it might be responsible for promoting death due to the risk of provoking thoracic or abdominal hemorrhage by vasoconstriction followed by hypertension (Frederick et al., 2010).

We disbelieve that the cases in which the colon was entrapped in the nephrosplenic ligament could have been solved only by phenylephrine infusion followed by exercising the horse. This is supported by the fact that these were the most difficult cases to correct and more than one rolling attempt was necessary in order to achieve its purpose. Additionally, the use of phenylephrine could be hazardous to the animals by itself, as formerly described (Frederick et al., 2010).

When considering the cases where the colon was displaced in between the body wall and spleen we could not identify for sure if the replacement was due to the rolling treatment or if it happened before, as previously described. However, the procedure indicated to be effective because it was efficient in correcting two out of the four cases in which the colon was completely entrapped into the nephrosplenic ligament.

Spontaneous repositioning of the displaced viscera is possible in cases of entrapment in between the spleen and body wall. However, in cases in which the large colon is exclusively entrapped in the nephrosplenic ligament, there is always requirement for specific intervention, such as surgery (Boening and von Saldern, 1985; Huskamp, 1987; Kalsbeek, 1989; Santschi et al., 1993). In cases where the clinical treatment fails, laparotomy should not be delayed for more than 30 minutes (Kalsbeek, 1989). 
Unsuccessful correction by rolling is not an indication for surgery and, instead, rolling could be tried more than once (Parks, 1996). In our surgical cases the animals were rolled thrice with no success before being sent to surgery, with no further delays.

Possible complications of rolling procedure include torsion of the cecal body, torsion of the large colon or an insufficient restoration of the circulation in the colonic wall (Kalsbeek, 1989). None of these signs were observed in short or long term for any of the animals rolled.

Complications after non-surgical correction alone appear to be minimal and non-surgical correction attempts do not place any additional risk for mortality if surgical intervention is performed later, given that good judgment in case selection is used (Boening and von Saldern, 1985; Sivula, 1991). When a patient is watched closely after the procedure, there is sufficient time to perform a laparotomy to correct any complications that might be caused by the procedure itself before it becomes irreparable (Kalsbeek, 1989).

Reported recurrence rates for nephrosplenic entrapment are 3.2-8.1\% (Huskamp and Kopf, 1980a; Baird et al., 1991; Hardy et al., 2000). In our case, only one animal had a recurrent nephrosplenic entrapment 10 months after its first non-surgical treatment.

Palpation of viscera per rectum is one of the best aids in diagnosing colic, and left displacement of the large colon can often be diagnosed on the basis of this examination alone (Boening and von Saldern, 1985; Huskamp, 1987; Kalsbeek, 1989; Santschi et al.,1993). Our rectal examination findings were similar to those reported by others (Abutarbush and Naylor, 2005). The ultrasound criterion for the diagnosis of left displacement of the large colon was the same as reported previously (Santschi et al., 1993).

The use of both diagnostic methods certainly reduced the possibility of diagnostic error (Abutarbush and Naylor, 2005). Transrectal examination alone is not entirely accurate (White, 1990). Similarly, ultrasonography independently might result in false negative results (Santschi et al., 1993; Parks, 1996).
As stated by Santschi et al. (1993), a rectal examination was performed immediately after the rolling procedure, with the animals still in lateral recumbence. Differently from the authors, our post-rolling ultrasonographic exams to confirm our rectal findings were performed only after anesthesia recovery. Our ultrasonographic findings before and after the rolling procedure were typically related to left displacement of the large colon and its subsequent correction (Santschi et al., 1993). The animals that needed surgery were sent to the OR after rectal palpation following three rolling attempts. A rectal examination was performed after each rolling attempt.

\section{CONCLUSIONS}

Non-surgical procedures can safely be used as the first choice of treatment to correct left displacement of the large colon. The ultrasound is a very helpful diagnostic tool when associated to rectal palpation in diagnosing left displacement of the large colon. When available, an ultrasound examination should always be performed. Despite being somewhat different from the others, our rolling technique showed to be effective in correcting left displacement of the large colon. Rolling the horse proved to be a harmless and uncomplicated procedure to perform, even when attempted more than once. Despite not confronting any complications, we reinforce the need for special attention to the animals after the procedure, in case any complications might occur in order to establish proper emergency and critical care procedures as soon as possible.

\section{REFERENCES}

ABUTARBUSH, S.M.; NAYLOR, J.M. Comparison of surgical versus medical treatment of nephrosplenic entrapment of the large colon in horses: 19 cases (1992-2002). J. Am. Vet. Med. Ass., v.227, p.603-605, 2005.

BAIRD, A.N.; COHEN, N.D.; TAYLOR, T.S. et al. Renosplenic entrapment of the large colon in horses: 57 cases (1983-1988). J. Am. Vet. Med. Ass., v.198, p.1423-1426, 1991.

BOENING, K.J.; von SALDERN, F. CHR. Die behandlung der Milz-Nieren-Band Aufhangung beim Pferd durch Walzen im Algemeinnarkose. Tierarztlich Umschau, v.4, p.252-257, 1985. 
BONFIG, H.; HUSKAMP, B. Zur therapie der Ver-lagerung des Colon ascendens in den Milznierenraum. Pferdeheilkunde, v.2, p.243251, 1986.

BURBA, D.J.; MOORE, R.M. Renosplenic entrapment: a review of clinical presentation and treatment. Equine Vet. Educ., v.9, p.180-184, 1997.

DEEN, T. Correcting left dorsal displacement of the large colon by hoisting and rolling. Vet. Med., v.85, p.284-288, 1990.

FREEMAN, D.E.; HAMMOCK, P.; BAKER, G.J. et al. Short- and long-term survival and prevalence of postoperative ileus after small intestinal surgery in the horse. Equine Vet. J., Suppl.32, p.42-51, 2000.

FREDERICK, J.; GIGUÈRE, S.; BUTTERWORTH, $\mathrm{K}$. et al. Severe phenylephrine-associated hemorrhage in five aged horses. J. Am. Vet. Med. Ass., v.237, p.830-834, 2010.

HACKETT, R.P. Nonstrangulated colonic displacement in horses. J. Am. Vet. Med. Ass., v.182, p.235-240, 1983.

HACKETT, R.P. Colonic displacement and volvulus - Diagnosis and surgical findings. Proc. Am. Assoc. Equine Pract., v.31, p.493-495, 1895.

HARDY, J.; MINTON, M.; ROBERTSON, J.T. et al. Nephrosplenic entrapment in the horse: a retrospective study of 174 cases. Equine Vet. J., Suppl. 32, p.95-97, 2000.

HARDY, J. Medical management of colics: fluid therapy and more. In: European Equine Meeting of the Year 2008 - XIV SIVE - FEEVA Congress, 2008, Venice. Proceedings..., Venice, 2008. p.124-130.

HUSKAMP, B. Displacement of the large colon. In: ROBINSON, N.E. (Ed) Current therapy in equine medicine. 2.ed. Philadelphia: WB SAUNDERS COMPANY, 1987. p.60-65.

HUSKAMP, B.; KOPF, N. Die Verlagerung des Colon ascendens in den Milz-Nieren-Raum beim Pferd (1). Tierärztliche Praxis, v.8, p.327-339, 1980a.

HUSKAMP, B.; KOPF, N. Die Verlagerung des Colon ascendens in den Milz-Nieren-Raum beim Pferd (2). Tierärztliche Praxis, v.8, p.495-506, 1980b.
KALSBEEK, H.C. Die rektale Korrektur des am Milz-nierenband eingeklemmten linken Kolons. Pferdeheilkunde, v.1, p.229-233, 1985.

KALSBEEK, H.C. Further experiences with non-surgical correction of nephrosplenic entrapment of the left colon in the horse. Equine Vet. J., v.21, p.442-443, 1989.

KOPF, M. (Ed) Current Therapy in Equine Medicine, 2.ed. London: W. B. SAUNDERS COMPANY, 1987. p.26.

MAIR, T.S.; SMITH, L.J. Survival and complication rates in 300 horses undergoing surgical treatment of colic. Part 3: Long-term complications and survival following a single laparotomy. Equine Vet. J., v.37, p.310-314, 2005.

MARKEL, M.D.; ORSINI, J.A.; GENTILE, D.G. et al. Complications associated with left dorsal displacement of the large colon in the horse. J. Am. Vet. Med. Ass., v.187, p.1379-1380, 1985.

MEZEROVA, J.; ZERT, Z. Long-term survival and complications of colic surgery in horses: analysis of 331 cases. Vet. Med., v.53, p.43-52, 2008.

PARKS, A.H. Displacement of the large colon: conservative versus surgical management. Comp. Cont. Educ. Pract. Vet., v.18, p.84-87, 1996.

SANTSCHI, E.M.; SLONE, D.E. Jr.; FRANK, W.M. Use of ultrasound in horses for diagnosis of left dorsal displacement of the large colon and monitoring its non surgical correction. Vet. Surg., v.22, p.281-284, 1993.

SIVULA, N.J. Renosplenic entrapment of the large colon in hoses: 33 cases (1984-1989). $J$. Am. Vet. Med. Ass., v.199, p.244-246, 1991

van den BOOM, R.; van der VELDEN, M.A. Short and long-term evaluation of surgical treatment of strangulating obstructions of the small intestine in horses: a review of 224 cases. Vet. Q., v.23, p.109-115, 2001.

WHITE, N.A. Examination and diagnosis of the acute abdomen. In: WHITE, N.A. (Ed) The Equine Acute Abdomen. Philadelphia: Lea \& Febiger, 1990. p.102-142. 